\title{
Training Evaluation in ICT Competencies for Career Guidance Counsellors: An Innovative Experience
}

\author{
Luis Martin Sobrado Fernández, $\mathrm{M}^{\mathrm{a}}$ Cristina Ceinos Sanz \\ University of Santiago de Compostela, Coruña, Spain
}

\begin{abstract}
The initial and continuing training of guidance career counselors should be characterized by a permanent professional development in carrying out new roles and skills for continuous improvement and innovation of guidance action. The main stages in the continuous development of guidance professionals are the diagnostic evaluation of their training needs: (1) defining objectives and core and essential competences, especially in their professional practice; (2) design and implementation of an appropriate training plan; and (3) assessment of skills acquired based on criteria and indicators and use of tools and resources for the respective assessment. At present, the professional profile of the guidance career counselors requires new skills, especially in the field of ICT (information and communication technologies), which must be integrated with guidance skills, articulating them on a map of skills needed in the training curriculum of these counselors and in their subsequent professional action. As an example of innovative learning experience in this field, the authors present the design of a program concerned with the guidance career professionals' development with 100 hours of time, which contains the objectives, contents, training methodology, teaching resources, and especially, the assessment process of it. As assessment resources, a continuous estimate was used through personal and group tasks by the use of the e-mail and Website, specially. In addition, an assessment questionnaire for the quality of the program was applied following a series of variables such as: gender, age, profile and professional role, course organization, training methodology, users' satisfaction, etc.. The high average of 8.9 points out of 10 in terms of overall satisfaction of participants in the program is highlighted. The reliability obtained from the instrument applied by the Cronbach's model was 0.91, which shows a high internal consistency.
\end{abstract}

Keywords: career, communication, competence, counsellor, evaluation, guidance, technology, training

\section{Introduction}

The necessary and essential training for guidance professionals is intimately connected with their personal and professional development, and now, it is regarded as a synthesis that integrates various elements, such as context, culture, knowledge and curriculum, general and specific guidance skills, ethical attitudes, methodological skills included in the ICT (information and communication technologies), creative and research competences, etc..

The term "professional development" agrees better than others similar, such as initial and/or continuous

Luis Martin Sobrado Fernández, Ph.D., senior professor, Faculty of Educational Sciences, Department of Research Methods and Educational Diagnostic, University of Santiago de Compostela.

$M^{\text {a }}$ Cristina Ceinos Sanz, Ph.D., assistant professor, Faculty of Educational Sciences, Department of Research Methods and Educational Diagnostic, University of Santiago de Compostela. 
training, retraining, updating, etc., with the meaning of the guidance counselor as an active agent, since it implies an evolution and progress interpretation beyond the traditional sense of the juxtaposition between initial training and professional development and it also represents an approach to the guidance counselor conception which highlights its contextual, cultural, and organizational character. According to Eraut (1997), it expresses a different cooperation model from the classical perspective of individualistic, psychometric, and clinical nature.

It is necessary for the above presentation linking the initial and continuing training of guidance practitioners with their personal, social, and labor development, since the training and professional development is a lifelong learning that should approach closely to the realization of labor tasks and occupational practice (Sparks, 1995).

For McCarthy (2004), the continuous training of guidance counselors throughout their lives has a dynamic and procedural nature and parts of the hypothesis of counseling practice as a real activity in a continued progress.

This new meaning to interpret the guidance counselor training, such as professional development, is linked up with the collaborative character guidance model which can be regarded as socio-educational agent, planner, manager, and evaluator of educational processes, and it can act in complex systems that make up the educational structure in areas that directly involve it (Collins \& Hiebert, 2002).

For Wilkins (1997), the initial training of guidance practitioners is only the beginning of a continuous process in the learning and professional development, and therefore, it requires a continuous preparation of counselors as close as possible to their labor practice to help them to keep alive and update the professional skills that their daily work demands to them.

The counselors' current role by Sobrado (2003) is based on the fact that initial training is insufficient for their work development that must be adapted, appropriately, to changing conditions of their profession (employment/unemployment), work context, and the users of their activity.

According to Watts and McCarthy (1998), in guidance practice, there are many problems in adjusting between initial training provided to guidance agents and the context where they develop their labor occupation.

The counselors' professional development must integrate processes and activities that improve the skills, attitudes, and abilities in their teaching roles. It also represents to improve their assessment ability on their own professional circumstances, career progression, and employment status (Sobrado, Fernández, \& Rodicio, 2012).

Guskey (2000) indicated that the professional development dimensions of guidance agents in education are mainly the following: reflection on guidance practice, educational progress with an improvement in the educational intervention, cognitive development with continuous acquisition of knowledge and progression in information processing strategies, self-knowledge and self-understanding with a balanced picture of yourself and professional career development through research and by undertaking new educational roles for guidance practice innovation and improvement.

\section{Professional Development of Career Counselors: The Role of Training}

In the present reality, the counselors' training is linked up with their professional development. It is understood as a synthesis that integrates different variables as core issues for the guidance professionalization.

Traditionally, training and professional development is perceived in a split way, not as antagonistic terms but as two different but related issues: one covering the culture that should be encouraged and learned (training); and the other covering the skills or strategies that should be applied (professional development). 
This new perception of training as professional development within a framework of innovation should be interpreted as a fundamental element based on the experience and collaborative praxis of an institutional nature. This approach shows the recognition of the counselor professional character in a labor field, where he/she can develop his/her activity. It also represents to recognize a social designer and manager agent of guidance processes and that often can act in the complex reality that shapes the social system which is usually unknown, even in themes and issues that are made daily.

The guidance professional, according to Hollis and Wantz (1993), as an agent of social and educational change, requires a review of the roles and competences of the vocational activity to observe if they configure it properly, and also their professionalization process and the culture that it develops.

Guidance counselors' training is a nuclear dimension of the quality of their role and it has significant repercussions on the development of the profession, the work practice, and the experiences of their occupational activity users (Kankaaranta, Grant, \& Linnakylä, 2007).

In the present situation, there is a prominent concern among the guidance professionals and in the researches about their training, concerning the implications that have innovations and technical advances in initial and continuous training.

The nuclear processes for carrying out a training program for counselors are the designing of strategic plans, the development of learning opportunities, the existence of organized teaching teams, the planning of a continuing professional development, the quality evaluation, and academic and professional training received.

The phases in the development of guidance practitioners' lifelong learning are the following ones: (1) diagnostic assessment of guidance needs and functions in connection with the strategic plan; (2) definition of the necessary objectives and skills to develop their guidance functions; (3) rating the skill levels of counselors interested in their professional training; (4) design and implementation of a training plan with their corresponding forms; (5) assessment of competences that were achieved, based on criteria, indicators, and evidence; and (6) their planning tools and resources to the corresponding assessment.

This training type is provided regularly to guidance counselors in many countries and their participation in which is usually optional. When it is required, the respective administration normally finances training and when it is optional a part of it is done by it and the other one by the attendees.

The motivation for participation, sometimes, includes improvements in salary or the penalty for the absence. In several countries, according to McCarthy (2004), the reward for participation is an accredited training or a promotion to a higher level of members of the professional association.

Regarding the methodology used in the guidance continuous training, in addition to the face-to-face training, it is the most common one, and ICT and distance education are only used a little. The low interest, in many European countries, to develop this type of training is in contrast to the high level in the United States of America, where the Association for Counselors' Training and Supervision develops and takes decisions to prepare guidance practitioners' online training (ACES (Association for Counselor Education and Supervision), 1999).

However, according to Sobrado and Ceinos (2011), the lack of financing and interest about the counselors' training by politicians and trainers, is contrasted with a significant motivation by the same practitioners and researchers; for example, with respect to the implications and advances in ICT in their preparation.

The European Congress held in 2002 on ICT (Cogoi, 2005) entitled "Quality and Ethics in Web-Based Guidance" (International Programme Office for Education and Training) defined the set of ICT skills that 
counselors should learn and made the following recommendations: (1) to explain the kind of theories that are appropriate for guidance on the Internet and assess them; (2) to provide access to counselors to train them in the use of ICT in their guidance actions; (3) to provide financing for such training; impart Web-based training modules to guidance agents; and (4) to give opportunities to prepare users to become skilled and confident in the use of Internet-based guidance resources and that practitioners must take responsibility for continuing professional development in this field.

\section{ICT in Guidance: Training Needs}

All instruments, media, and resources that make up ICT in recent years, have generated continuous transformations, with their corresponding consequences and influences in different sectors of our lives, so the area of guidance has not been unaware of such mutations (Educational Assessment and Counselling Institute, 2007). These tools have been introduced widely in all fields, becoming, at present, common and even essential elements. Similar to what happened in other areas, little by little, there is a greater presence of these resources in the counselor, which has meant that this discipline and its practitioners are engaged in a change and transformation process, so they have to face the challenges proposed, adapt to the demands and claims, and consequently, adopt new roles and functions, so it is necessary for the acquisition and development of new skills, mainly, those of a technological nature (Cogoi, 2009).

The use and application of these resources in guidance favor multiple possibilities (assessment, diagnosis and self-diagnosis, advice, guidance and counseling, information and communication, training and research, and administration and management of guidance processes and actions) (Ceinos, 2008, 2009a; Sobrado \& Ceinos, 2011), understanding that they must be conceived to uphold or support an element, despite the possibility offered to develop and implement distance guidance processes, also known as the name "virtual guidance", which is a new way of guidance based, primarily, on the concept of "flexibility" (Barroso \& Cabero, 2010).

As a result of the issues discussed so far, without losing sight of changes and transformations that at present continue to occur in the society in which we find ourselves, a new model of intervention has appeared and has been consolidated gradually, being sometimes questioned. The technological model is characterized mainly, by making available a series of instruments and useful tools for the counselor, which must be conceived as a collaborative and supportive element in guidance intervention processes, and may not ever be an exclusive model. The authors are, therefore, faced with "a model of intervention necessary to address changes, transformations, requirements and demands made by the Information and knowledge society" (Ceinos, 2009a, p. 194). However, despite many and diverse applications that ICT offer in the guidance field, the use made of these will be conditioned by a number of variables, highlighting, among them, the objectives they seek to achieve, the media and resources at our disposal, the users involved in these processes, as well as the knowledge and critical skills that counselors and guided subjects have (Sobrado, 2004).

According to all the ideas presented, the counselor profile requires new competences, abilities, and skills that allow the use of technological tools in guidance (Sobrado \& Ceinos, 2010). Thus, only with the acquisition, development, and internalization of these skills, will you be able to implement the new roles and functions that this group has to face as a result of the emergence of such tools, also, favoring, at the same time, an optimal development in a personal and professional way.

For the acquisition of all these skills: firstly, a positive attitude towards ICT will be necessary, 
understanding them as a basic element of the current culture and society. Subsequently, different training processes will favor the gradual discovery of the enormous potential and possibilities that these tools offer in the guidance field, while they will allow the acquisition of the necessary technological skills, familiarity, and greater confidence in them, and therefore, the reduction of fear and insecurity generated when it is time to make use of them. Consequently, given the need to use such instruments, the requirements, and demands that, nowadays, the current society is raising, the professional profile of this group should be reconsidered, as well as the contents and models that shape their training processes (Sobrado, 2006).

The current trend in the technology training of counselors should stop focusing so exclusively on ICT training models based mostly on the instrumental dimension or mastery degree of such tools, being necessary, today, training activities that promote appropriate training to raise the technological innovations. Consequently, training initiatives should help to integrate ICT into the development of guidance activities. In other words, training proposals aimed to the counselors should encourage the development of a knowledge that goes beyond training for the technical use of these media, leading to a knowledge that fosters an understanding of the multiple possibilities offered by these resources, the integration of these tools based on real needs that are identified, and the adoption of a critical and reflective perspective about it. Therefore, the issue is to develop practical knowledge so that these media and tools become a daily instrument in guidance centers and services, demonstrating its utility in different situations that the group of counselors must address.

\section{Integration of ICT and Guidance Skills in Career Counseling}

One of the challenges that, today and increasingly, in the immediate future, the responsible people on the guidance systems have to face with is the use of ICT not only in the management and recording of information concerned, but also with respect to the provision of services through these media, which considers the need to establish priorities to attend in order to provide an answer to the changes caused by the inclusion of technology resources in guidance (Ceinos, 2008). This question requires the acceptance and development of new functions to counselors, making it necessary to do formative activities aimed at this group in order to acquire the necessary skills and abilities to know, to become familiar with and use technology tools to carry out their professional work (Cogoi, 2005). It is in this context that there is a need to conduct training activities in relation to the use of ICT in guidance, to enable their users in the use of such tools.

Among the existing requirements to carry out formative activities to promote the training of counselors as far as ICT resources are concerned, there is little and somewhat vague identification and definition of competences and basic skills to use these tools in counselors' professional practice, so it is considered necessary to structure both types of skills and integrate those of guidance character with the technological ones (Sobrado, Ceinos, \& García, 2010).

The articulation of guidance and technology skills, from a personal point of view, is a primary tool for guidance professionals, through which they can explore their training needs and job profile, and encourage its development (Sobrado, 2008). By complementing this aspect with the utility it can offer in the educational activities design process and professional development of initial and continuous character with regard to the use of ICT in the guidance function.

To carry out the task of articulating guidance and technological skills, it was taken as starting point the guidance competences issued by IAEVG (International Association Educational Vocational Guidance) in 
2003, and the relationship of ICT skills developed by FEDORA (European Forum for Academic Guidance) in 2008 .

Table 1

Competences in the Field of Guidance and ICT

\begin{tabular}{|l|l|}
\hline Guidance competence (Iaevg, 2003) & Technological skill (Fedora, 2008) \\
\hline Core competences & $\begin{array}{l}\text { Core skills } \\
\text { Specialized competences: }\end{array}$ \\
- Assessment & $\begin{array}{l}\text { - Word processor } \\
\text { - Educational guidance }\end{array}$ \\
- Career development & - Presentation skills \\
- Counseling & - Databases \\
- Information management & - Graphics \\
- Consultation and coordination & - E-mail \\
- Research and evaluation & - Internet/Intranet \\
- Program/service management & - Environment for distance learning Network as a user \\
- Community capacity building & Environment for distance learning Network as an \\
- Placement & administrator. \\
\hline
\end{tabular}

Later, each of the guidance competences within their groups was defined in connection with each technology with respect to how it can be used and how it could be used prospectively, seeking a balance between a definition that covered all common uses and those that can be expected in the future (see Table 1). Additionally, the authors used two dimensions more, one referring to the way of ICT use in guidance - as a medium, as a resource or development of guidance materials and contents based on ICT - and the other related to the categories taxonomy of objectives and learning outcomes in the form of knowledge, attitudes, and skills. All these dimensions are articulated through a matrix table of specifications leading, consequently, to a competences map where ICT skills joint with guidance competences, characterizing such instrument, by its openness and flexible character, in order to incorporate other new ones, especially, in the technology skills field, given its continuous improvement and the constant appearance of other different and innovative ones (Sanz, Gil, \& Marzal, 2007a; 2007b) (see Figure 1).

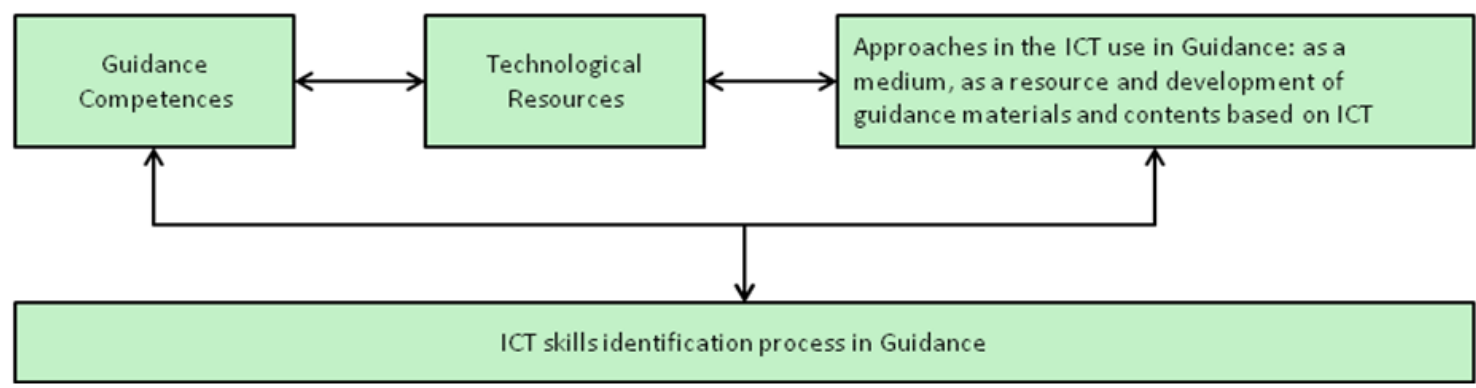

Figure 1. Variables used in the process of identifying ICT skills in guidance. Source: Sobrado \& Ceinos, 2009, p. 139.

Finally, in order to clarify the task of articulating the ICT skills and guidance competences, the authors present the Table 2 which shows the technological skills related to the e-mail and Websites in order to 
implement the different guidance responsibilities.

\section{Table 2}

The Use of E-mail and Websites Related to Guidance Competences

E-mail (R: resource, M: medium, D: development)

Diagnostic: Developing the ability...

- To get information in order to diagnose the customers' needs accurately. (M)

Educational guidance: Developing the ability...

- To encourage the communications establishment with the counselor in service customers via e-mail. (R)

- To respond through such resource to the guidance needs of each client. (M)

Professional development: Developing the ability...

- To communicate via email, appropriately and with sensitivity, to different agents in order to do professional development activities. (R)

- To use the e-mail as a support in the professional development of customers service. (M).

Information management: Developing the ability...

- To help customers to request information, advice and guidance through the use of email. (R)

- To provide and transmit information through this resource. (M)

Research and evaluation: Developing the ability...

- To follow-up actions about the progress experienced by the client via email. (M)

Placement: Developing the ability...

- To explain to the client how to get information on job vacancies from other information sources. (R)

- To train/prepare the client in job search and work offers. (M)

Websites (R: resource, M: medium, D: development)

Diagnostic: Developing the ability...

- To make use of on-line resources to diagnose the customers' needs. (R)

- To explain to service users the on-line tools possibilities for self-assessment. (R)

- To do on-line designs about ways to conduct the self-assessment. (D)

Educational guidance: Developing the ability...

- To use Web pages specialized and of official institutions as a resource to access to large information sources, offering the relative to the existing educational and training offer in the different educational levels. (R)

- To teach users how to explore existing Websites in order to obtain useful information for them. (R)

- To design a Web site applied for Educational Guidance. (D)

Professional development: Developing the ability...

- To identify and use relevant Websites which exist for the subject career development. (R)

- To make use of the forums related to the professional development. (R)

- To explain and demonstrate to customers' service the use that they can make of existing guidance resources on Websites. (R)

- To use forums in order to offer help in the professional development process. (M)

- To design a Web page that offers the possibility to contact and establish communications with the users group. (D)

Counseling: Developing the ability...

- To locate Websites with online information resources and good quality guidance tools during the development of individual and group guidance interviews. (R) 
(Table 2 continued)

- To explain to users the possibilities of use offered by existing guidance resources on the Web. (R)

- To design self-help tools for Web space focused for advice. (D)

Information management: Developing the ability...

- To use and select Web sites in search and official information location tasks and for administrative purposes. (R)

- To help clients find and use information available on the Web pages themselves. (R)

- To create contents for Websites of information and research ways to sail in the Web. (D)

Research and evaluation: Developing the ability...

- To explain to customers how to use assessment tools. (R)

- To plan an evaluation section on a Website. (D)

Placement: Developing the ability...

- To use the on-line information resources in order to know job offers and placement. (R)

- To search for employment opportunities with the client. (R)

- To design on Website a section related with job offers and labor experiences. (D)

Note. Source: Ceinos, 2008.

\section{Designing a Training Project of Guidance Professionals}

Currently, career professionals' training is linked to their personal and labor development, as their professional training is a lifelong learning which should be very close to the occupational tasks performance. In this sense, it can be affirmed that the need to conduct continuous training actions to help and encourage counselors to acquire and update skills demanded by their work tasks. Therefore, the practitioners' professional development must integrate training processes and activities, whose basic aim is to the improvement of their abilities, attitudes and skills, acquire others with innovative character, while it represents a progression in their personal and professional career (Sobrado, 1996).

At present, the guidance counselor profile requires new skills, which allow, among other things, the use of tools of ICT in guidance, answering in this way, to one of the most necessary demands (Ceinos, 2009b). Training activities in order to promote appropriate training to raise innovations with technological resources are essential in order to favor, at once, the integration of these media in the development and implementation of guidance activities. It is, therefore, possible, to enable an applied knowledge in career guidance professionals so that technological tools become a daily element in guidance centers and services, demonstrating, in this way, their utility in different situations that they have to face (Cabero, Romero, Barroso, Román, Llorente, \& Castaño, 2007).

For this purpose, we present, in general, a training program design of 100 hours for a career guidance professionals group in order to favor, in the same group, the discovery of the possibilities offered by the ICT, the acquisition of necessary technological skills, and familiarity of this group with these tools, all aspects which result in less uncertainty and insecurity that, sometimes, the media can have on counselors. The objectives formulated, the contents addressed, and the methodology and resources used in its implementation are shown below:

The objectives are:

(1) To consider the role of ICT in guidance field; 
(2) To present the framework of core and specialized competences in the guidance context;

(3) To analyze the ICT skills used in guidance actions;

(4) To present a map of guidance skills integrated with ICT competences;

(5) To develop a training model for counselors in ICT and an assessment project of the quality counseling activities.

The contents are:

(1) Guidance skills table;

(2) ICT skills guide;

(3) Integrated map of guidance and ICT competences;

(4) Training and professional development models of counselors in the ICT context;

(5) Criteria evaluation and quality standards of guidance actions.

The training methodologies are:

(1) Teaching exposition of the program and planned contents;

(2) Interactive discussion with participants;

(3) Development of provided tasks;

(4) Processes and results evaluation.

The teaching resources are technological and printed tools, such as $\mathrm{CD}$, pendrive, video, Internet, PowerPoint, books, etc..

\section{Evaluation of the Career Counselors’ Professional Development Program}

One of the phases to be considered in the development of guidance counselors' lifelong learning is the evaluation of these training activities, by which the main results of the training activity and/or proposal previously presented are shown. For this purpose, the implementation of the evaluative task, a continuous assessment and a final evaluative tool of the quality and satisfaction of teaching activities carried out were applied. The reliability coefficient obtained by Cronbach's model in the assessment instrument used was 0.91 , which proves its high internal consistency.

Based on the previous ideas, the main results of this process are presented below.

\section{Quality Assessment Questionnaire}

Personal and professional profile (analysis of the results in percentages). The results about gender are shown in Figure 2.

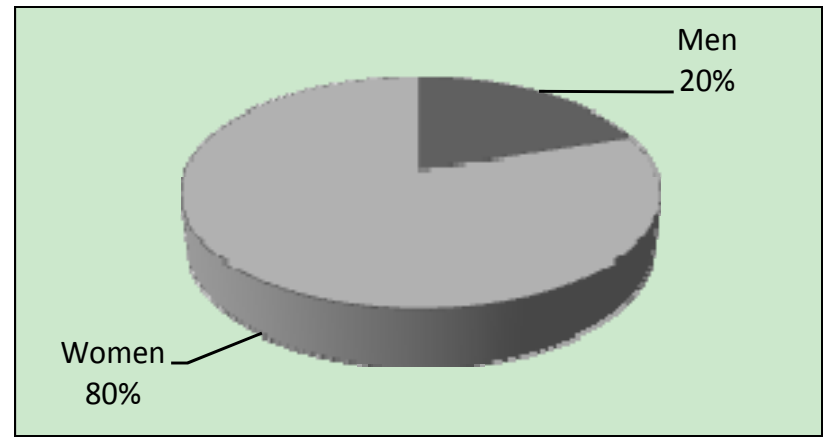

Figure 2. Sample distribution by gender. 
Considering the distribution of the sample by gender, the $80 \%$ of professionals surveyed are women, compared with the $20 \%$ represented by the male group. Consequently, we have a predominant female group.

The results about age are shown in Figure 3.

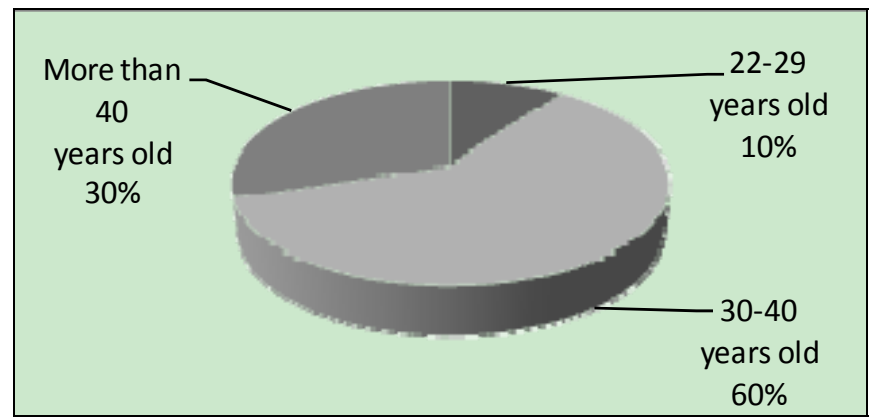

Figure 3. Sample distribution by age.

The age of the professionals surveyed varied, mostly between 22 and 40 years old, so this is a young group. Ten percent of the samples are $22-29$ years old, the $60 \%$ are $30-40$ years old, and only the remaining $30 \%$ are over 40 years old.

The results about professional status are shown in Figure 4.

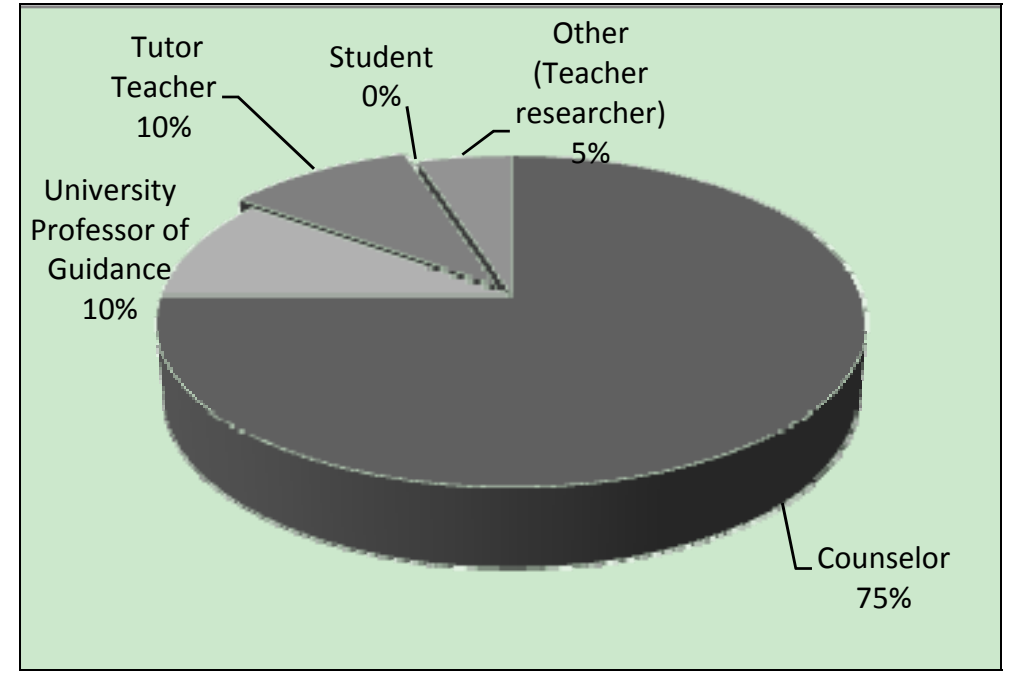

Figure 4. Sample distribution based on professional status.

With regard to their professional situation, we can say that the entire sample is in active, being the following played roles: counselor $(75 \%)$, university professor of guidance $(10 \%)$, tutor $(10 \%)$, and researcher teacher (5\%).

In summary, in view of the results shown, we can say that the female group prevails, represented by $80 \%$ of the sample and aged at 30-40 years old (70\%) and over 40 years old (30\%). With regard to their professional profile, all participants in the seminar are working and the predominant role they play is the counselor one $(75 \%)$.

Learning action assessment. In the assessment process of the training activity designed, an evaluation questionnaire was applied in order to know the quality and satisfaction of the teaching activities that were 
carried out. The instrument used, the items related to issues such as organization, contents, methodology, media, and resources, and the results obtained in each one are presented as follows.

As guidelines for completing the questionnaire referred, the following ones indicated (see Table 3):

Assess the following aspects of the program using a rating scale of 0 to 10 ( 0 the lowest and 10 the highest) (Write down their evaluation points for each question, giving them the score that is most suitable in the appropriate box).

Example: If you think that the question 3: "The contents of the course were quite adjusted on schedule", you write an " 8 " in the box next to the rating.

Table 3

Averages Obtained in the Different Aspects of the Program Assessment Questionnaire

\begin{tabular}{lll}
\hline Item & Program assessment questionnaire & Average (0 to 10) \\
\hline 1 & $\begin{array}{l}\text { The course was well organized (information, fulfillment dates/schedules, and delivery of teaching } 9 \\
\text { materials ...). }\end{array}$ & 9.6 \\
2 & Participants in the group were adequate for its development. & 8.5 \\
3 & Contents in the program were adapted to the plan. & 8.9 \\
4 & The thematic units were adjusted to their own training needs. & 8.7 \\
5 & There was an appropriate mixture between theory and practical application. & 7.3 \\
6 & The time course was sufficient according to its objectives and contents. & 9.3 \\
7 & The schedule favored the course development and attendance. & 9.2 \\
8 & The system of the course delivery facilitated the learning. & 8.7 \\
9 & The teacher knew the issues in depth. & 9.4 \\
10 & The teacher was able to resolve problems and questions adequately. & 9.6 \\
11 & The teacher created a climate that favored the learning. & 9.2 \\
12 & The documentation and materials provided were understandable and appropriate. \\
13 & The teaching materials were updated. & 8.4 \\
14 & The exercises and case studies were adapted to their own training needs. & 9.3 \\
15 & The guidelines and training materials allowed the Workshop to be performed easily. & 8.6 \\
16 & Media of support were sufficient. & 8.7 \\
17 & As an assistant, the course allowed me to acquire new skills/abilities that I can apply later. & 8.8 \\
18 & As a participant, I expanded my knowledge to advance in my professional career. & 8.8 \\
19 & The program encouraged their personal development. & 9
\end{tabular}

In view of the results shown in Figure 5, it should be noted firstly the average score obtained, which reaches a value of 8.89 over 10, thus, we are able to say that it is in a quality formative action, according to the assessment made to this by its participants. With respect to organizational aspects or issues of the course, the scores achieved in the items related to these issues get a score at or above 9, highlighting the items specifically referred to the organization and adequacy of the training activity to the users' number, both aspects with a score of 9 and 9.6, respectively.

In terms of content and topics addressed, the first ones were adapted to the previously planned, valued aspect with a score of 8.5, and the subjects were also adjusted to the training needs identified (8.9), so that these dimensions were rated positively. 
With regard to the methodology used, it should be noted the existing adequacy between theory and practice (8.7), as well as exercises and practical cases given to the training needs of their users (9.3).

The resources also obtained very favorable results, being considered updated (8.4), favoring the course development (8.6), sufficient (8.7), and adequate and understandable (9.2). On the other hand, the time-related aspects also obtained outstanding scores, since the duration of this based on the objectives and content raised scored 7.3, while the schedule established to encourage and support its development reached a value of 9.3. With regard to the teacher responsible for delivering this training activity, it should be noted that he or she knew the issues addressed deeply (8.7), resolved the doubts and problems adequately (9.4), and created a climate that favors learning (9.6).

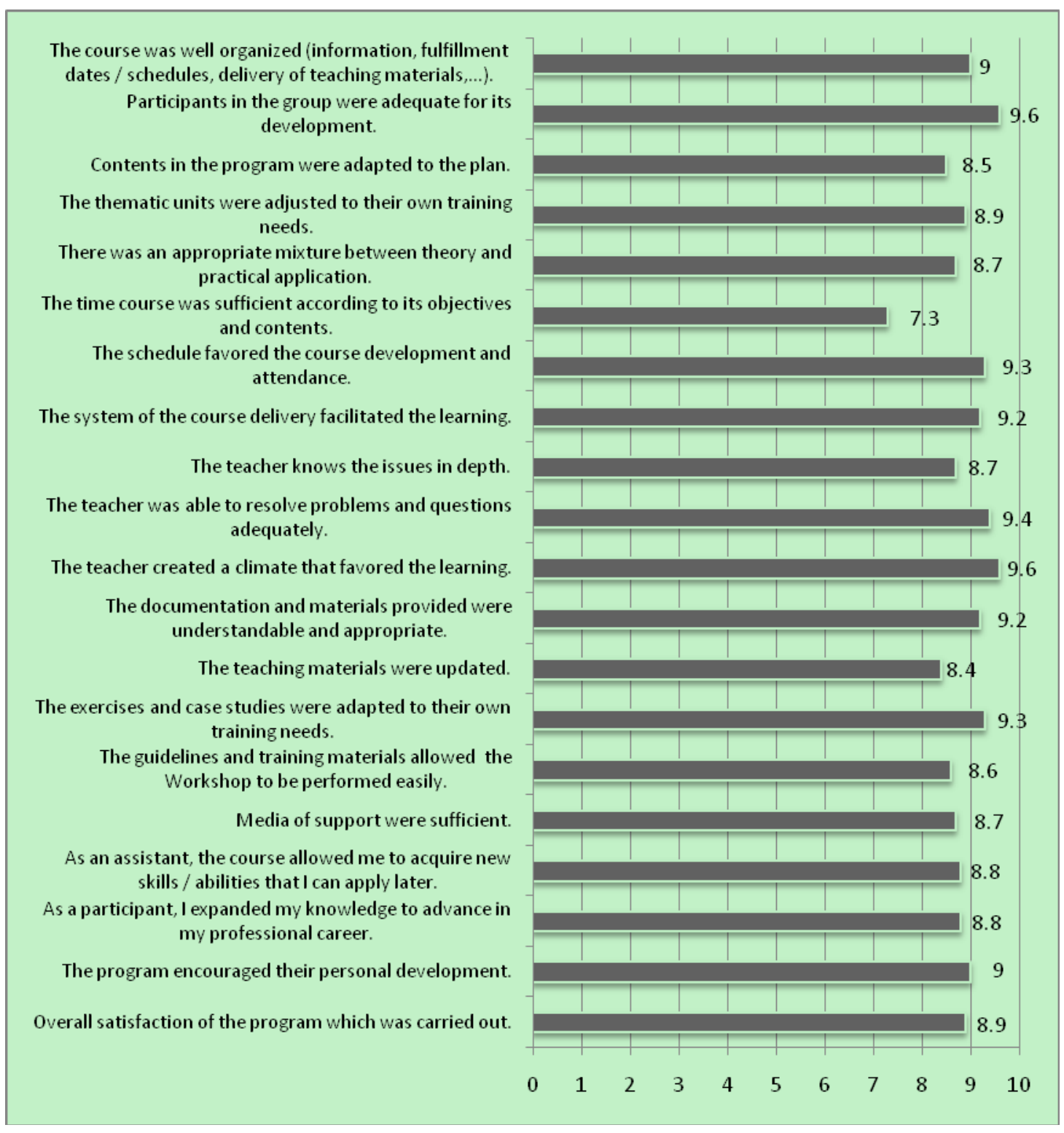

Figure 5. Averages of the program assessment questionnaire items. 
Thus, the course allowed to acquire the skills and capabilities proposed, which have practical application (8.8), and served at the same time, to broaden the users knowledge, which favored the progress in their career (8.8), and also provided their personal development (9); all aspects as discussed above are fundamental and essential in the development of a training action, which, on the whole, was valued in terms of their degree of satisfaction by their users with a high score of 8.9 out of 10 .

\section{Synthesis}

The initial and continuous training of career professionals should be understood as a career training and lifelong learning that encourage their personal and professional development, issues that will acquire new skills and update the already internalized ones in order to answer to the changing conditions of its occupational activity (Sobrado, Fernández, Ceinos, \& García, 2010).

Currently, the guidance field and the professionals that develop their labor function in it are not strange to the continuous and deep transformations in all areas and sectors, making it necessary to design and develop training activities in order to facilitate their adaptation to the changing situation in which we live (Velaz de Medrano, 2008).

More particularly, it must not lose sight of the technological revolution experienced in recent years; thus, preparation activities aimed at the digital literacy of this group are required. Therefore, the importance of these in the learning process of guidance practitioners is highlighted, and the identified needs, the consistent defining objectives and competences, the training plan design and the evaluation of its quality and the competences achieved must be considered. All aspects are projected onto the teaching experience exposed in the present research.

\section{References}

ACES (Association for Counselor Education and Supervision). (1999). Guidelines for on-line instruction in counselor education. Alexandria, V. A.: American Counseling Association.

Barroso, J., \& Cabero, J. (2010). Educational research in ICT: Practical views. Madrid: Summary.

Cabero, J., Romero, R. (Coords), Barroso, J., Román, P., Llorente, Mª. C., \& Castaño, C. (2007). Design and production of the ICT for training. Barcelona: UOC.

Ceinos, C. (2008). Diagnosis of the labor counselors competences in the use of the information and communication technologies. (Doctoral dissertation, University of Santiago de Compostela: Publication Service)

Ceinos, C. (2009a). Information and communication technologies (ICT) in vocational guidance. In L. Sobrado, \& A. Cortés (Coords). (2009). Vocational guidance: New scenes and perspectives. Madrid: New Library.

Ceinos, C. (2009b). Technological tools in vocational guidance: Assessment of the use of information and communication technologies by guidance agents. Educational Galician Journal, 43, 166-170.

Cogoi, C. (2009). Skill 2: ICT tools and training for e-guidance practitioners. Bologna: Aster.

Cogoi, C. (2005). Using ICT in guidance: Practitioner competences and training. Bolonia: Outline Edizioni.

Collins, S., \& Hiebert, B. (2002). Developing a competency framework for career counselor training. In H. Suzin (Ed.), Natcon Papers 2002. Toronto: Career Centre, University of Toronto.

Educational Assessment and Counseling Institute. (2007). The ICT in education. Madrid: Education and Science Department.

Eraut, M. (1997). Developing professional knowledge and competence. Londres: The Falmer Press.

Fedora. (2008). Guidance and counseling. Aarhus: Counselling and Support Centre of University.

Guskey, T. (2000). Evaluating professional development. Thounsand Oaks, C. A.: Cortin Press Inc.

Hollis, J., \& Wantz, R. (1993). Counselor preparation (Vol. 1: Programs and personnel). Municie, I. N.: Accelerated Development Inc.

Iaevg. (2003). International competences for guidance practitioners. Newsletter, 46, 5. 
Kankaanranta, M., Grant, A., \& Linnakylä, P. (Eds.). (2007). E-portfolio: Adding value to lifelong learning. Jyvaskyla: University Press.

McCarthy, J. (2004). The skills, training and qualifications of guidance workers. International Journal for Educational and Vocational Guidance, 4, 159-178.

Sanz, J., Gil, J. M., \& Marzal, A. (2007a). A computing tool for counseling. Journal of Educational Research, 25(2), 305-326.

Sanz, J., Gil, J. M., \& Marzal, A. (2007b). Computing tools for vocational guidance and counseling. Journal of Psychoeducational Research Journal, 5(1), 83-102.

Sobrado, L. (1996). Counselling training and professionalization: Models and processes. Electronics Journal of Research and Educational Assessment (RELIEVE) (Vol. 2, No. 2-3). Retrieved from http://www.uv.es/RELIEVE/v2n2/RELIEVEv2n2_3. htm

Sobrado, L. (2003). The counselors professional development. Professionalization, 75, 25-76.

Sobrado, L. (2004). Use of information and communication technologies (ICT) by guidance counselors. Galician Teaching Journal, 43, 89-106.

Sobrado, L. (2006). Counselors competences in the ICT field. Journal of Educational Studies, 11, 27-43.

Sobrado, L. (2008). The ICT and the counselors competences. In IX Permanent Seminary of Vocational Guidance. Barcelona: Universität.

Sobrado, L., Fernández, R. E., Ceinos, C., \& García, M. R. (2010). The role of ICTs in the e-training and guidance throughout life: Analysis of the European situation. Spanish Journal in Guidance and Psychopedagogy, 21(2), 271-282.

Sobrado, L., Fernández, R. E., \& Rodicio, Ma. L. (2012). Educational guidance: New perspectives. Madrid: New Library.

Sobrado, L., \& Ceinos, C. (2009). Design of ICTs competences map involved in the work of guidance professionals. Bordón, 61(3), 137-149.

Sobrado, L., \& Ceinos, C. (2010). Planning and development of an ICT skills map in guidance. Communicate, XVIII(35), 167-174.

Sobrado, L., \& Ceinos, C. (2011). Information and communication technologies use in the vocational guidance and training. Madrid: New Library.

Sobrado, L., Ceinos, C., \& García, R. (2010). Model of ICT skills and new professional profile of the guidance counselors in some European countries. Bilingual International Journal: Guidance and Society, 8, 201-210.

Sparks, D. (1995). A paradigm shift in staff development. The ERIC Review, 3(3), 2-4.

Velaz de Medrano, C. (2008). Training and professionalization of guidance counselors from a competence viewpoint. Education $X X 1,11,155-181$.

Watts, A., \& McCarthy, J. (1998). Training in community based guidance assistance: A formative evaluation. Dublin: National Centre for Guidance in Education.

Wilkins, P. (1997). Personal and professional development for counselors. London: Save. 